\title{
S2P3-R (v1.0): a framework for efficient regional modelling of physical and biological structures and processes in shelf seas
}

\author{
R. Marsh ${ }^{1}$, A. E. Hickman ${ }^{1}$, and J. Sharples ${ }^{2,3}$ \\ ${ }^{1}$ University of Southampton, National Oceanography Centre, Southampton, UK \\ ${ }^{2}$ School of Environmental Sciences, University of Liverpool, Liverpool L69 3BX, UK \\ ${ }^{3}$ National Oceanography Centre, Liverpool, Joseph Proudman Building, 6 Brownlow Street, Liverpool L3 5DA, UK \\ Correspondence to: R. Marsh (rma@noc.soton.ac.uk)
}

Received: 17 December 2014 - Published in Geosci. Model Dev. Discuss.: 30 January 2015

Revised: 28 August 2015 - Accepted: 11 September 2015 - Published: 8 October 2015

\begin{abstract}
An established one-dimensional (1-D) model of Shelf Sea Physics and Primary Production (S2P3) is adapted for flexible use in selected regional settings over selected periods of time. This Regional adaptation of S2P3, the S2P3-R framework (v1.0), can be efficiently used to investigate physical and biological phenomena in shelf seas that are strongly controlled by vertical processes. These include spring blooms that follow the onset of stratification, tidal mixing fronts that seasonally develop at boundaries between mixed and stratified water, and sub-surface chlorophyll maxima that persist throughout summer. While not representing 3-D processes, S2P3-R reveals the horizontal variation of the key 1-D (vertical) processes. S2P3-R should therefore only be used in regions where horizontal processes - including mean flows, eddy fluxes and internal tides - are known to exert a weak influence in comparison with vertical processes. In such cases, S2P3-R may be used as a highly versatile research tool, alongside more complex and computationally expensive models. In undergraduate oceanography modules and research projects, the model serves as an effective practical tool for linking theory and field observations. Three different regional configurations of S2P3-R are described, illustrating a range of diagnostics, evaluated where practical with observations. The model can be forced with daily meteorological variables for any selected year in the reanalysis era (1948 onwards). Example simulations illustrate the considerable extent of synoptic-to-interannual variability in the physics and biology of shelf seas. In discussion, the present limitations of S2P3-R are emphasised, and future developments are outlined.
\end{abstract}

\section{Introduction}

In a global context, the shelf seas are disproportionately productive due to the continuous supply of nutrients (Holt et al., 2009a, and references therein). A variety of models have been developed to explore the processes that shape and maintain productivity. Operational biogeochemistry and ecosystem models typically represent the system with relatively high complexity and resolution, e.g. the $7 \mathrm{~km}$ Atlantic Margin Model NEMO-ERSEM (AMM7-NE) system (Edwards et al., 2012) - see also http://www.metoffice.gov.uk/research/ news/marine-predictions. Such models may perform well alongside observations, but simulations rely on high performance computing resources such that extensive experimental work is consequently not practical.

In contrast to complex models, the Shelf Sea Physics and Primary Production (S2P3) model (Simpson and Sharples, 2012) exploits the dominance of vertical processes over horizontal processes in shelf seas. S2P3 explicitly represents vertical heat fluxes, vertical mixing of momentum and vertical mixing of heat and tracers (nitrate and chl $a$ concentrations). Central to the model physics is a turbulence closure scheme, determining the light environment and nutrient fluxes that drive a simple primary production (nutrient phytoplankton - NP) model. Phytoplankton growth responds to changes in stratification and mixing. In this way, S2P3 can efficiently simulate the seasonal cycle of stratification and primary production at a selected location, characterized by a local depth and tidal current amplitude. In particular, S2P3 has been used (e.g. Sharples, 2008) to simulate idealized seasonal tidal mixing fronts (TMFs), analogous to the observed discontinuities 
between mixed and seasonally stratified water in mid-latitude shelf seas (Simpson and Hunter, 1974). While controlled to the first order by vertical processes, the transition from mixed to stratified water across a TMF typically occurs on a horizontal scale of $\sim 10-20 \mathrm{~km}$ (e.g. Moore et al., 2003); therefore, for clear resolution of associated physical and biogeochemical structures, TMFs are ideally simulated at high horizontal resolution $(1-2 \mathrm{~km})$.

S2P3 was introduced as "PHYTO-1D" and originally described in Sharples (1999). An updated version of PHYTO1D was described in Sharples (2008). The model is designed for use as an investigative (and educational) tool (see zipped material at http://pcwww.liv.ac.uk/ jons/model.htm). S2P3 has been used as a research tool to establish the varying influence of winds and air-sea heat fluxes on inter-annual variability in the timing of stratification and the spring bloom in the northwestern North Sea (Sharples et al., 2006), and to quantify the impact of spring-neap tidal cycles on biological productivity at TMFs (Sharples, 2008). In educational contexts, S2P3 and forerunner models have been used for around 10 years in year 3 undergraduate and masters level postgraduate teaching at the Universities of Southampton and Liverpool, in the UK.

In spite of potential for widespread application, S2P3 has not been extensively used and tested across real transects or in limited regions, where the model can be appropriately used for investigating time-evolving stratification and biological productivity. Introduced here, S2P3-R is a framework for using S2P3 to efficiently model physical and biological structures in shelf seas, for selected years during the reanalysis era (Kalnay et al., 1996). The development of S2P3-R has facilitated the simulation of vertical processes and their horizontal variability in real time, for quick investigation of ongoing changes and detailed fieldwork planning.

In the remainder of the paper, we first outline the S2P3-R framework. We start with a brief description of the physical and biological components of S2P3, followed by details of the modified source code, model performance and diagnostic options. This is in turn followed by details on model set-up in different domains (horizontal meshes and tidal forcing), and the specification of meteorological forcing. We then evaluate model simulations for three different regions, undertaken and diagnosed using the new framework. In discussion, some important caveats are emphasised, and we outline the prospects for development of the S2P3-R framework.

\section{The S2P3-R framework}

\section{$2.1 \quad$ S2P3}

Here, we provide a brief description of the physical and biological components of S2P3, emphasising key equations. For a more detailed model description, the reader is referred to Sharples (1999, 2008).

\subsubsection{Physical model}

Central to the physics of $\mathrm{S} 2 \mathrm{P} 3$ is a turbulence closure scheme, for which the prognostic variable is turbulent kinetic energy (TKE), formally defined as $q^{2} / 2$, where $q$ is the turbulent intensity, or velocity scale $\left(\mathrm{m} \mathrm{s}^{-1}\right)$. For a tidal current with $x$ and $y$ components $u$ and $v$, the tendency of TKE is expressed as

$$
\begin{aligned}
\frac{\partial}{\partial t}\left(\frac{q^{2}}{2}\right) & =\frac{\partial}{\partial z}\left(K_{q} \frac{\partial}{\partial z}\left(\frac{q^{2}}{2}\right)\right)+N_{z}\left[\left(\frac{\partial u}{\partial z}\right)^{2}+\left(\frac{\partial v}{\partial z}\right)^{2}\right] \\
& +K_{z}\left(\frac{g}{\rho} \frac{\partial \rho}{\partial z}\right)-\frac{q^{3}}{B_{1} l}
\end{aligned}
$$

where $\rho$ is density, quadratic in temperature $T$ ( $\rho=$ $1028.11-6.24956 \times 10^{-2} T-5.29468 \times 10^{-3} T^{2}$, assuming a constant salinity of 35.00$), B_{1}$ is a constant of the closure scheme, $K_{q}$ is the vertical eddy diffusivity for TKE, $K_{z}$ is the vertical eddy diffusivity for other scalar properties, $N_{z}$ is vertical eddy viscosity, and $l$ is an eddy length scale $\left(l=\kappa z(1-z / h)^{0.5}\right.$, at depth $z$, given total depth $h$ and von Karmen's constant $\kappa=0.41$ ). Forward time stepping is explicit throughout, with time steps, $\Delta t$, constrained by the diffusive stability criterion, $\Delta t<\Delta z^{2} / 2 N_{z}$, given depth intervals, $\Delta z$.

Tides and winds force the TKE profile for given boundary conditions:

$q_{z=h}^{2}=B_{1}^{2 / 3} \frac{\tau_{\mathrm{s}}}{\rho_{z=h}}$,
$q_{z=0}^{2}=B_{1}^{2 / 3} \frac{\tau_{\mathrm{b}}}{\rho_{z=0}}$,

where $\tau_{\mathrm{s}}$ is the surface $(z=h)$ stress due to the wind, and $\tau_{\mathrm{b}}$ is the near-bottom $(z=0)$ stress due to tidal currents. The $x$ and $y$ components of wind stress are obtained as

$$
\begin{gathered}
\tau_{\mathrm{s} x}=-c_{\mathrm{d}} \rho_{\mathrm{a}} u_{w} \sqrt{\left(u_{w}^{2}+v_{w}^{2}\right)}, \\
\tau_{\mathrm{s} y}=-c_{\mathrm{d}} \rho_{\mathrm{a}} v_{w} \sqrt{\left(u_{w}^{2}+v_{w}^{2}\right)}
\end{gathered}
$$

given a drag coefficient $c_{\mathrm{d}}\left(c_{\mathrm{d}}=(0.75+0.067 w) \times 10^{-3}\right.$, for wind speed $w)$, air density $\rho_{\mathrm{a}}\left(=1.3 \mathrm{~kg} \mathrm{~m}^{-3}\right)$, and $u_{w}$ and $v_{w}$, the $x$ and $y$ components of wind. The $x$ and $y$ components of near-bottom stress are obtained as

$$
\begin{gathered}
\tau_{\mathrm{b} x}=-k_{\mathrm{b}} \rho_{0} u_{1} \sqrt{\left(u_{1}^{2}+v_{1}^{2}\right)}, \\
\tau_{\mathrm{b} y}=-k_{\mathrm{b}} \rho_{0} v_{1} \sqrt{\left(u_{1}^{2}+v_{1}^{2}\right)}
\end{gathered}
$$

given a drag coefficient $k_{\mathrm{b}}(=0.003)$, representative density for seawater $\rho_{0}\left(=1025 \mathrm{~kg} \mathrm{~m}^{-3}\right)$, and $u_{1}$ and $v_{1}$ (the $x$ and $y$ components of the current $1 \mathrm{~m}$ above the seabed); see Sharples (1999) for further details on the subsequent calculation of $K_{z}, K_{q}$ and $N_{z}$. 
In addition to mixing, the water column is locally heated and cooled. The tendency of temperature $(T)$ is obtained at each depth level as

$$
\frac{\partial T}{\partial t}=\frac{\partial}{\partial z}\left(K_{z} \frac{\partial T}{\partial z}\right)+Q_{\mathrm{h}}(z)
$$

where $z$ is height above the seabed and $Q_{\mathrm{h}}(z)$ is the net heating at $z$.

Heat fluxes are formulated as follows. We first define a surface net heat flux $\left(Q_{\text {net }}\right)$ as the sum of incoming shortwave radiation $\left(Q_{\mathrm{SW}}\right)$, long-wave back radiation $\left(Q_{\mathrm{LW}}\right)$, and latent and sensible heat exchange with the atmosphere $\left(Q_{\text {sens }}\right.$ and $\left.Q_{\text {lat }}\right)$ :

$Q_{\text {net }}=Q_{\text {sw }}-\left(Q_{\mathrm{LW}}+Q_{\text {sens }}+Q_{\text {lat }}\right)$.

Incoming shortwave radiation, irradiance in the presence of clouds, is calculated as

$$
Q_{\mathrm{SW}}=\left(1.0-0.004 C-0.000038 C^{2}\right) Q_{\mathrm{SW}, \mathrm{c}-\mathrm{s}},
$$

where $C$ is cloud fraction, and clear-sky irradiance, $Q_{\mathrm{sw}, \mathrm{c-s}}$, is obtained as

$Q_{\mathrm{sW}, \mathrm{c}-\mathrm{s}}=S(1-\alpha) f(\theta, t)\left(1-\kappa_{\mathrm{SW}}\right)$,

where $S$ is the solar constant $\left(=1368 \mathrm{~W} \mathrm{~m}^{-2}\right), \alpha$ is an atmospheric albedo $(=0.24), f(\theta, t)$ is a function representing the daily and seasonal variation in day length at latitude $\theta$, and $\kappa_{\mathrm{SW}}$ is a shortwave absorption coefficient $(=0.06)$. Long-wave radiation is calculated as

$$
\begin{aligned}
& Q_{\mathrm{LW}}= \\
& \quad \varepsilon_{\mathrm{LW}}\left(1.0-0.6 \times 10^{-4} C^{2}\right)\left(0.39-0.05 q^{0.5}\right) \sigma T^{4},
\end{aligned}
$$

where $\varepsilon_{\mathrm{LW}}$ is long-wave emissivity $(=0.985), q$ is vapour pressure $\left(q=R q_{\mathrm{s}}\right.$, given saturated vapour pressure $q_{\mathrm{s}}(T)$ and relative humidity $R$ ), and $\sigma$ is the Stefan-Boltzmann constant $\left(\sigma=5.67 \times 10^{-8} \mathrm{~W} \mathrm{~m}^{-2} \mathrm{~K}^{-4}\right)$. Sensible heat flux is calculated using the bulk formula

$Q_{\text {sens }}=\rho_{\mathrm{a}} c_{p} C_{h} U\left(T_{\mathrm{s}}-T_{\mathrm{a}}\right)$,

where $c_{p}$ is the specific heat capacity of air $\left(c_{p}=\right.$ $\left.1004 \mathrm{~J} \mathrm{~kg}^{-1} \mathrm{~K}^{-1}\right), C_{h}$ is a transfer coefficient $\left(C_{h}=1.45 \times\right.$ $\left.10^{-3}\right), U$ is surface wind speed, $T_{\mathrm{S}}$ is the sea surface temperature, and $T_{\mathrm{a}}$ is surface air temperature. Latent heat flux is calculated using the bulk formula

$Q_{\text {lat }}=\rho_{\mathrm{a}} L_{v} C_{e} U\left(q_{\mathrm{s}}-q\right)$,

where $L_{v}$ is the specific heat capacity of air $\left(L_{v}=2.5 \times\right.$ $\left.10^{6}-2.3 \times 10^{3} T_{\mathrm{s}}\right)$, and $C_{e}$ is a transfer coefficient $\left(C_{e}=\right.$ $1.5 \times 10^{-3}$ ).

The surface net heat flux is partitioned down the water column as follows. The red end of the spectrum, $55 \%$ of shortwave radiation, is assumed to be absorbed at the top depth level; hence, the surface heating, $Q_{\mathrm{h}, 0}=0.55 Q_{\mathrm{SW}}-\left(Q_{\mathrm{LW}}+\right.$ $\left.Q_{\text {sens }}+Q_{\text {lat }}\right)$. The remaining $45 \%$ of insolation is available for heating at lower levels, distributed exponentially throughout the water column as a heating rate $Q_{\mathrm{h}}(z)$, according to

$\frac{\partial Q_{\mathrm{h}}}{\partial z}=-Q_{\mathrm{h}}(z)\left(\lambda_{0}+\varepsilon X_{T}(z)\right)$,

where $\lambda_{0}$ is an attenuation coefficient $\left(\lambda_{0}=0.1 \mathrm{~m}^{-1}\right)$ and $\varepsilon$ is a pigment absorption cross section $\left(\varepsilon=0.012 \mathrm{~m}^{2}\right.$ $\left.(\mathrm{mg} \mathrm{chl})^{-1}\right)$, accounting for shading due to $X_{T}(z)$, the local chlorophyll $a$ ( $\mathrm{chl} a$ ) concentration $\left(\mathrm{mg} \mathrm{chl} \mathrm{m}^{-3}\right)$, taking $X_{T}(z)=q^{\text {chl }} P_{\mathrm{C}}$, for the cell chl $a$ : carbon ratio, $q^{\text {chl }}$ $\left(0.03 \mathrm{mg} \mathrm{chl}(\mathrm{mg} \mathrm{C})^{-1}\right)$, and carbon concentration, $P_{\mathrm{C}}$ (see below).

\subsubsection{Biological model}

Phytoplankton is modelled in terms of an equivalent carbon concentration $\left(P_{\mathrm{C}}\right.$; units $\left.\mathrm{mg} \mathrm{C} \mathrm{m}^{-3}\right)$ and internal cellular nitrogen $\left(P_{\mathrm{N}}\right)$. In each grid cell, $P_{\mathrm{C}}$ tendency is due to the net effect of vertical mixing, growth and grazing, according to

$$
\frac{\partial P_{\mathrm{C}}}{\partial t}=\frac{\partial}{\partial z}\left(K_{z} \frac{\partial P_{\mathrm{C}}}{\partial z}\right)+\mu P_{\mathrm{C}}-G P_{\mathrm{C}}
$$

given a grazing impact rate, $G$, and a growth rate, $\mu$, that is a function of photosynthetically active radiation:

$\mu=\mu_{\mathrm{m}}\left(1-e^{-\left(\alpha I_{\mathrm{PAR}} \theta / \mu_{\mathrm{m}}\right)}\right)-r^{B}$,

where $\alpha$ is the maximum quantum yield, $I_{\mathrm{PAR}}$ is the light availability, $\theta$ is the chl $a$ : carbon ratio, $r^{B}$ is the respiration rate, and the maximum growth rate, $\mu_{\mathrm{m}}$, is given by

$\mu_{\mathrm{m}}=1.16 \times 10^{-5}\left(\frac{Q-Q_{\text {sub }}}{Q_{\mathrm{m}}-Q_{\text {sub }}}\right) 0.59 e^{0.0633 T}$,

where $Q=P_{\mathrm{N}} / P_{\mathrm{C}}$ is the cell nitrogen quota, $Q_{\text {sub }}$ is the subsistence nutrient : carbon quota, and $Q_{\mathrm{m}}$ is the maximum cell quota. The tendency for phytoplankton nitrogen $\left(P_{\mathrm{N}}\right)$ is similarly described as

$\frac{\partial P_{\mathrm{N}}}{\partial t}=\frac{\partial}{\partial z}\left(K_{z} \frac{\partial P_{\mathrm{N}}}{\partial z}\right)+u P_{\mathrm{C}}-G P_{\mathrm{N}}$,

where the uptake rate $u$ is obtained as a Michaelis-Menton function of the dissolved inorganic nitrogen (DIN) concentration:

$u=\left[u_{\mathrm{m}}\left(1-\frac{Q}{Q_{\mathrm{m}}}\right) \frac{\mathrm{DIN}}{\left(k_{\mathrm{u}}+\mathrm{DIN}\right)}\right]+\left\{\begin{array}{l}\mu Q, \mu<0 \\ 0, \mu \geq 0\end{array}\right.$

given $k_{\mathrm{u}}$, a half saturation coefficient for nutrient uptake, and $u_{\mathrm{m}}$, a maximum nutrient uptake rate. The uptake of nitrogen leads to a tendency in DIN:

$\frac{\partial \mathrm{DIN}}{\partial t}=\frac{\partial}{\partial z}\left(K_{z} \frac{\partial \mathrm{DIN}}{\partial z}\right)-\mu P_{\mathrm{C}}+e G P_{\mathrm{N}}$, 
Table 1. Boundaries, resolution, tidal forcing, initial temperature and meteorological forcing for each domain (POLCOMS is Proudman Oceanographic Laboratory Coastal Ocean Modelling System; OTPS is OSU Tidal Prediction Software).

\begin{tabular}{|c|c|c|c|c|c|}
\hline Domain & Boundaries & Resolution & Tidal Forcing & Initial temperature field & Meteorological forcing \\
\hline $\begin{array}{l}\text { Northwest } \\
\text { European shelf }\end{array}$ & $\begin{array}{l}14.917^{\circ} \mathrm{W}- \\
1.917^{\circ} \mathrm{E} \\
48.056^{\circ} \mathrm{N}- \\
61.944^{\circ} \mathrm{N}\end{array}$ & $\begin{array}{l}0.167^{\circ} \text { (longitude) } \\
0.111^{\circ} \text { (latitude) } \\
(\sim 12 \mathrm{~km})\end{array}$ & $\begin{array}{l}\text { M2, S2, N2 } \\
\text { (POLCOMS) }\end{array}$ & $\begin{array}{l}10.1^{\circ} \mathrm{C} \text { everywhere } \\
\text { (default) }\end{array}$ & $\begin{array}{l}\text { Daily climatology for the } \\
\text { Celtic Sea (Sharples, 2008) }\end{array}$ \\
\hline $\begin{array}{l}\text { Western } \\
\text { English Channel }\end{array}$ & $\begin{array}{l}4-6^{\circ} \mathrm{W} \\
49.5-50.5^{\circ} \mathrm{N}\end{array}$ & $\begin{array}{l}1^{\prime} \times 1^{\prime} \\
(\sim 1 \mathrm{~km})\end{array}$ & $\begin{array}{l}\mathrm{M} 2, \mathrm{~S} 2, \mathrm{~N} 2 \\
\text { (POLCOMS } \\
\text { interpolated) }\end{array}$ & $10.1^{\circ} \mathrm{C}$ everywhere & $\begin{array}{l}\text { Daily NCEP reanalysis data } \\
\text { for grid square centred on } \\
5^{\circ} \mathrm{W}, 50^{\circ} \mathrm{N}\end{array}$ \\
\hline $\begin{array}{l}\text { East China and } \\
\text { Yellow seas }\end{array}$ & $\begin{array}{l}112-130^{\circ} \mathrm{E} \\
21-42^{\circ} \mathrm{N}\end{array}$ & $\begin{array}{l}0.083^{\circ} \times 0.083^{\circ} \\
(\sim 6 \mathrm{~km})\end{array}$ & $\begin{array}{l}\text { M2, S2, N2, O1, } \\
\text { K1 (OTPS) }\end{array}$ & $\begin{array}{l}\text { After 1-year started } \\
\text { from } 15.1^{\circ} \mathrm{C} \\
\text { everywhere }\end{array}$ & $\begin{array}{l}\text { Daily NCEP reanalysis data } \\
\text { for grid square centred on } \\
125^{\circ} \mathrm{E}, 32.5^{\circ} \mathrm{N}\end{array}$ \\
\hline
\end{tabular}

where $e$ is the fraction of grazed phytoplankton cellular nitrogen recycled immediately back into the dissolved nitrogen pool.

Water column nitrogen is constantly restored towards an initial winter concentration, $\operatorname{DIN}_{0}\left(\mathrm{mmol} \mathrm{m}^{-3}\right)$, by a flux of inorganic nitrogen from the seabed:

$$
\frac{\partial \mathrm{DIN}_{1}}{\partial t}=\frac{f_{\mathrm{DIN}}}{\Delta z}\left(1-\frac{\mathrm{DIN}_{1}}{\mathrm{DIN}_{0}}\right)
$$

where DIN $_{1}$ is the dissolved nitrogen in the bottom depth cell of the model grid, $\Delta z(\mathrm{~m})$ is the thickness of the model grid cell, and $f_{\text {DIN }}\left(\mathrm{mmol} \mathrm{m}^{-2} \mathrm{~s}^{-1}\right)$ is the maximum flux of dissolved nitrogen from the seabed into the bottom depth cell.

The values of biological parameters $\left(G, \mu_{\mathrm{m}}, \theta, r^{B}, Q_{\text {sub }}\right.$, $\left.\alpha, u_{\mathrm{m}}, Q_{\mathrm{m}}, k_{\mathrm{u}}, e, \mathrm{DIN}_{0}, f_{\mathrm{DIN}}\right)$ are as listed in Table I of Sharples (2008).

\subsection{Modified S2P3 source code, performance and diagnostics}

For the S2P3-R framework, we modified the Fortran 90 source code of S2P3 v7.0, which includes additional commands and sub-routines to facilitate the Winteracter Fortran graphical user interface (GUI) toolset (Interactive Software Services Ltd., www.winteracter.com), the model being supplied with a text book (Simpson and Sharples, 2012) as an executable application that runs under the Windows operating system. This source code was modified for compilation and execution in a Unix environment by removing GUI-related lines of code. These changes are solely to facilitate compilation and execution in Unix environments, and S2P3 is thus far unchanged as a scientific tool.

Within the new framework, S2P3 can be used to generate geographically specific maps, sections and time series, with varying run-time implications on a single processor. Maps typically comprise 5000-20000 grid points, while sections comprise 10-100 grid points. For a given year (see below), maps can take over a day to generate (depending on the ex- tent of shallower water, where shorter time steps are necessary), while sections typically take a few minutes, and annual time series at a single location typically take a few seconds.

Default mapped variables are the mid-summer surfacebottom temperature difference, annual-mean surface heat flux, and annual net production. Other quantities, such as the mid-summer sub-surface chl $a$ maximum (SCM) and SCM depth, can also be mapped. The option for simulating sections is motivated by opportunities for direct comparison with measurements obtained through surveys and cruises. In selecting to simulate section data, constant depth intervals are specified for plotting on a regular distance-depth mesh without the need for interpolation. The option for time series at single locations is motivated by the availability of time series at repeat conductivity-temperature-depth (CTD) stations and moorings. Finally, we save daily horizontal distributions of physical and biological variables for selected periods, to generate animations that yield a range of insights not so easily appreciated with individual maps or sections.

FORTRAN programmes are used to post-process model data for plotting, and MATLAB scripts are used to plot model variables (as used to prepare the figures and animations presented here). Example MATLAB plotting scripts are provided together with the source code and other ancillary programmes and data files in s2p3-reg.zip (see "Code availability").

\subsection{Regional configurations}

Three domains have been developed and tested here, for reasons that are outlined in turn. Figure 1 shows the bathymetry, while Table 1 specifies the boundaries, resolution, tidal forcing and initial temperature field, for each domain. In an initial stage of development, S2P3-R was developed for the northwest European shelf domain. Development of the two other domains has been motivated by the extent to which the different climatological and tidal forcings can be accommodated (in the shelf seas around China) and by ongoing fieldwork 

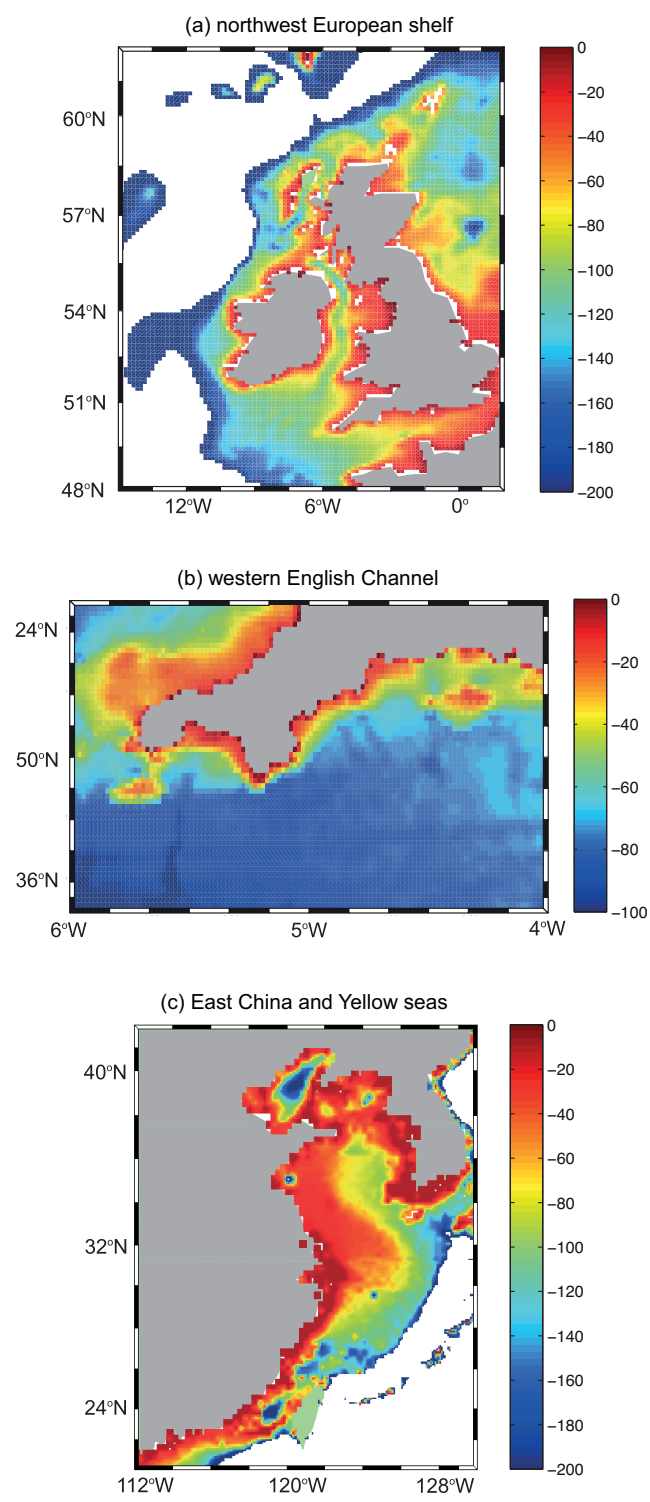

Figure 1. Bottom depth (relative to sea surface) in the three S2P3-R domains: (a) northwest European shelf; (b) western English Channel; (c) East China and Yellow seas.

(annual surveys south of Cornwall) in a smaller region where the tidal mixing front is particularly sharp.

Bathymetry is typically in the range $50-100 \mathrm{~m}$ across most of the northwest European shelf (Fig. 1a). However, some important details are emphasised for the other two domains: a shallower inshore zone (depths $<30 \mathrm{~m}$ ) in the western English Channel (Fig. 1b); a secondary shelf break (descending 50-100 m) in the East China Sea (Fig. 1c). At very high resolution, some artefacts of bathymetric surveying are apparent as linear features in the bathymetry south of Cornwall (Fig. 1b).

For the northwest European shelf, bathymetry and current amplitudes for the leading three tidal constituents (M2, S2,
N2 - see Fig. S1 in the Supplement) were obtained from the Proudman Oceanographic Laboratory Coastal Ocean Modelling System (POLCOMS) model (e.g. Holt et al., 2009b). For the western English Channel, bathymetry is extracted from the ETOPO1 global relief model (Amante and Eakins, 2009) and tidal current amplitudes are interpolated from the POLCOMS data set. For the East China and Yellow seas, current amplitudes for the leading 13 tidal constituents were generated using OTPS (OSU Tidal Prediction Software), based on the inverse method developed by Egbert et al. (1994) and Egbert and Erofeeva (2002), and bathymetry is selected within the OTPS system. Opting to use the leading five constituents for this region, S2P3 was adapted to include the two diurnal constituents, $\mathrm{O} 1$ and $\mathrm{K} 1$, in addition to the semi-diurnal constituents S2, M2 and N2 (see Fig. S2).

One further distinction in regional set-up concerns initial temperatures. At 1 January of each year, the water column across the European shelf seas is presumed mixed everywhere. In the default model, initial temperature is $10.1^{\circ} \mathrm{C}$ at all depths, appropriate for the Celtic Sea. This initial temperature is also appropriate for the western English Channel, although we specify simulated 31 December temperatures (constant through the fully mixed water column) for subsequent 1 January dates in the case of simulations at the Western Channel Observatory (see Sect. 3.2). Elsewhere, alternative values for initial temperature are appropriate, consistent with local climate. Consider as an example the northeast subregion of our northwest European shelf domain. Sensitivity tests illustrate the importance of specifying an appropriate initial temperature - see Fig. S3. If the initial temperature in this region is too high (Fig. S3a), the net heat fluxes will fall below $-10 \mathrm{~W} \mathrm{~m}^{-2}$ across much of the domain, especially to the north (i.e. annual net cooling from a "warm start"), while if the temperature is too low (Fig. S3b), heat fluxes will exceed $10 \mathrm{~W} \mathrm{~m}^{-2}$ at most locations (i.e. annual net warming from a "cold start"). Only if the initial temperature is accurate to within around $1{ }^{\circ} \mathrm{C}$ do we avoid strong annual net cooling or heating (Fig. S3c). For the China seas, we specify a higher initial temperature of $15.1^{\circ} \mathrm{C}$ and simulate 2 consecutive years, accounting for weak wintertime stratification in this region. We analyse only the second year, for which more realistic initial conditions are thus established across the wider domain (on 1 January of the second year).

\subsection{Meteorological forcing}

In addition to tidal mixing, S2P3 is forced with surface heat fluxes and wind stirring. Heat is gained by shortwave radiation and lost via long-wave back-radiation, sensible and latent heat fluxes - see Eq. (6). Shortwave radiation varies with latitude and time of year, and decreases with fractional cloud cover - see Eqs. (7) and (8). Long-wave radiation varies with sea surface temperature and cloud cover - see Eq. (9). Sensible and latent heat losses vary with air temperature, wind 

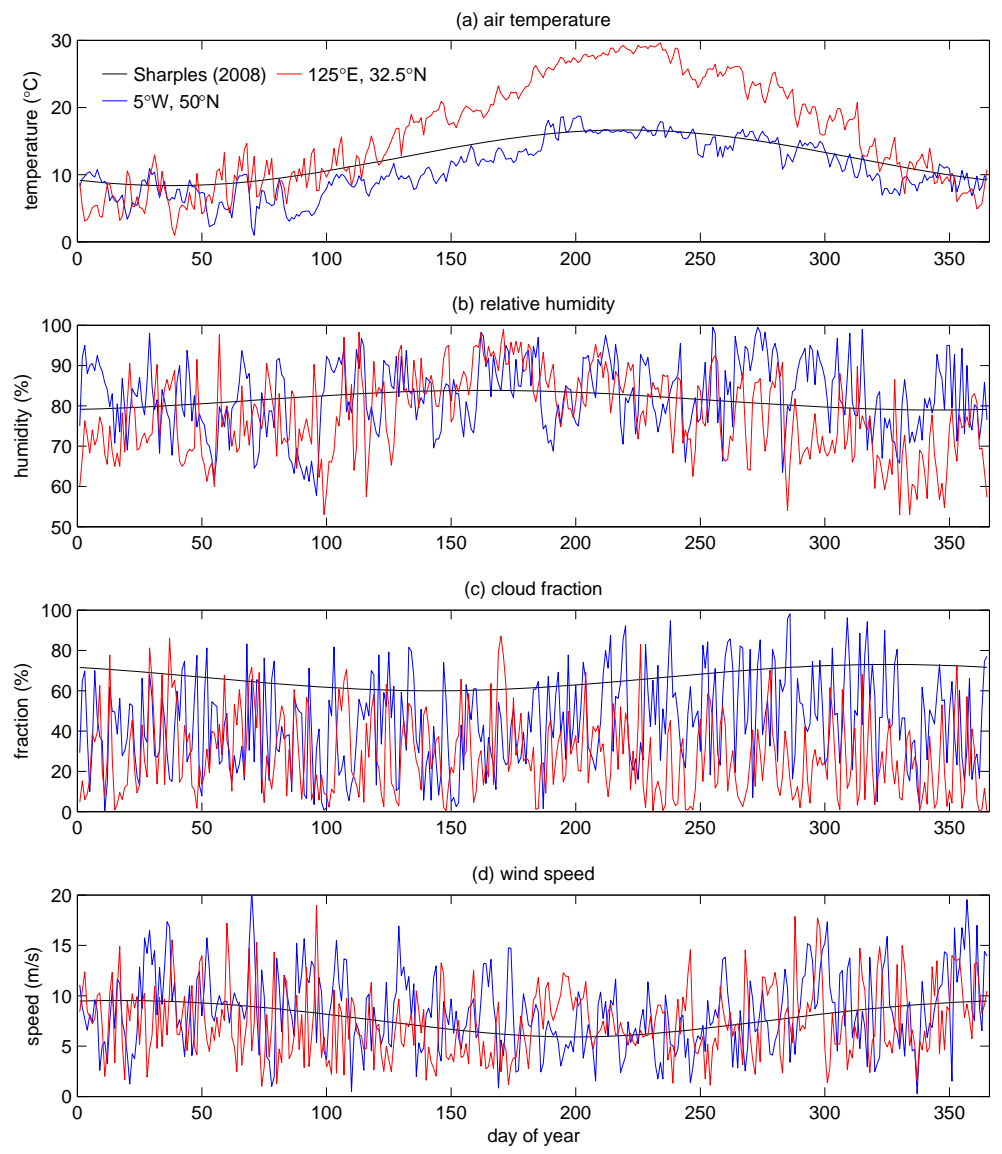

Figure 2. Daily meteorological data: climatological for the northwest European shelf (Sharples, 2008), and for 2013 in the western English Channel, and in the East China and Yellow seas: (a) air temperature; (b) wind speed; (c) cloud fraction; (d) relative humidity.

speed and relative humidity according to bulk formulae - see Eqs. (10) and (11).

Daily values for the four necessary meteorological variables are provided in a single ASCII file. Sharples (2008) uses climatological meteorological data for the Celtic Sea, while Sharples et al. (2006) use meteorological data for 1974-2003 from weather stations in the vicinity of a study site in the northwestern North Sea. Here, we use NCEP reanalysis data provided by the NOAA/OAR/ESRL PSD, Boulder, Colorado, USA, from their website at http://www. esrl.noaa.gov/psd/. These data are routinely updated to within a day or so of the present time, and span the period from 1948. The data are provided on a $2.5^{\circ}$ global mesh, so each domain is forced everywhere with meteorological data from a single $2.5^{\circ}$ grid square, central to that region. Coordinates of selected grid squares are listed in Table 1.

Figure 2 illustrates time series of meteorological variables for the three domains. In initial testing, for the northwest European shelf, we use the "default" Celtic Sea climatology (Sharples, 2008). For the other two domains, data for 2013 are shown for example. Note the extent of high-frequency synoptic variability in these cases, in particular for relative humidity, cloud fraction and wind speed. Also note that the UK spring of 2013 was exceptionally cold, hence air temperatures for the western English Channel sub-domain considerably below the Celtic Sea climatological average. Also note considerable contrast between the maritime and continental climates, for the European shelf and China seas, respectively.

\section{Model evaluation in the new framework}

\subsection{Northwest European shelf}

Figure 3 shows a summary of fields obtained for a simulation using the northwest European shelf domain. Figure 3a shows the annual-mean Hunter-Simpson parameter, $\log _{10}\left(h / u^{3}\right)$, where $h$ is the local depth and $u$ is the amplitude of the local tidal current. Previous studies (starting with Simpson and Hunter, 1974) have established a threshold value of around 2.7, below (above) which the water column is well-mixed (stratified); $\log _{10}\left(h / u^{3}\right)$ is generally below 2.7 throughout the southern North Sea, and across much of the eastern English Channel and the Irish Sea. These regions are indeed well-mixed throughout summer, as evident 

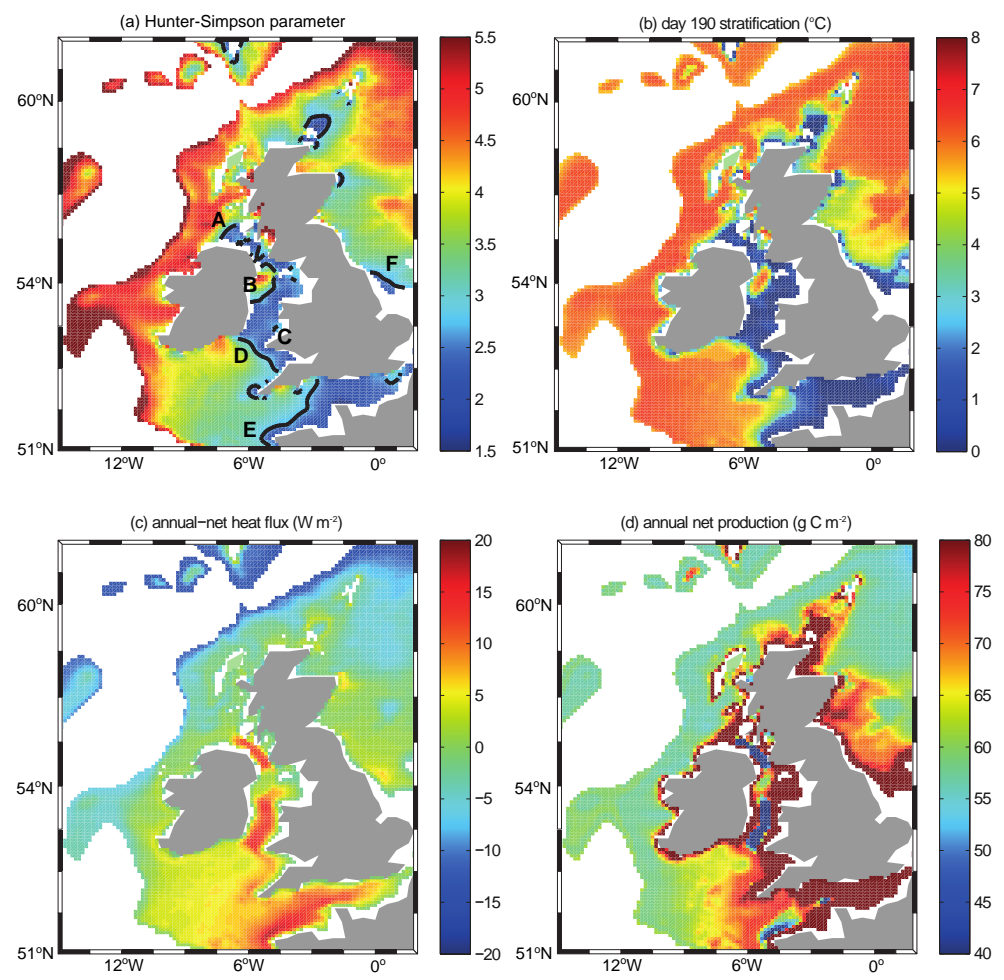

Figure 3. For the northwest European shelf domain: (a) Hunter-Simpson parameter, highlighting the contour delineating $\log _{10}\left(h / u^{3}\right)=2.7$; (b) day 190 surface-bottom temperature difference; (c) net surface heat flux; (d) annual net production. In (a), we label fronts as in Fig. 8.1 of Simpson and Sharples (2012): the Islay front (A); the western Irish Sea front (B); the Cardigan Bay front (C); the St. Georges Channel front (D); the Ushant and western English Channel front (E). We additionally label the Flamborough frontal system (F).

in near-zero surface-bottom temperature differences for midJuly, shown in Fig. 3b. Elsewhere, stratification is established, and the model hence simulates a set of fronts between mixed and stratified water that are clearly observed in satellite data (see Fig. 8.1 in Simpson and Sharples, 2012 - also indicated in Fig. 3a): the Islay front between Northern Ireland and Scotland (A); the western Irish Sea front enclosing a seasonally stratified region of the Irish Sea (B); part of the Cardigan Bay front (C); the St George's Channel front between Wales and Ireland (D); and the Ushant and western English Channel front between southwest England and Brittany, France (E). The model also simulates a front observed between the seasonally stratified northern North Sea and the permanently mixed southern North Sea, including the Flamborough frontal system (Hill et al., 1993, and references therein), also indicated (F) in Fig. 3a.

A limitation of the simulation presented in Fig. 3 is the use of default climatological meteorological forcing, originally set up for simulating tidal mixing fronts in the Celtic Sea. This has important consequences for local heat balances, evaluated here with the annual-mean surface net heat flux, shown in Fig. 3c. In the central Celtic Sea (south of Ireland), the net heat flux is slightly positive, in the range $0-5 \mathrm{~W} \mathrm{~m}^{-2}$. Elsewhere, one might expect that a warmer (cooler) sea surface will lead to stronger net heat loss (gain), via sensible and latent heat fluxes. However, the imbalance reaches a maximum of $10 \mathrm{~W} \mathrm{~m}^{-2}$ in the warm southwest English Channel (net heating) and a minimum of $-10 \mathrm{~W} \mathrm{~m}^{-2}$ in the cool northern North Sea (net cooling). This is consistent with insolation levels at these latitudes that are respectively higher and lower than that for the Celtic Sea. Such imbalances are also a consequence of specifying the same initial temperature everywhere (see Sect. 2.2), such that the northern North Sea is initially too warm (so must lose heat over the seasonal cycle), and the southwest English Channel is initially too cool (so must gain heat). Net heat fluxes are also notably positive in some regions that are well-mixed all year round, in particular the Irish Sea and parts of the English Channel. This is consistent with enhanced heat storage due to mixing throughout the water column of heat gained in summer (Simpson and Bowers, 1984).

We have also experimented, on the northwest European shelf domain, with spatially discriminate initial temperatures and meteorological forcing (not shown here), the latter respecting variation of NCEP reanalysis data (per $2.5^{\circ}$ grid square) across the domain. While this approach has the potential to restrict net heat fluxes closer to zero at all locations, coarse-resolution data must be carefully interpolated to the relatively fine $12 \mathrm{~km}$ mesh of S2P3-R in order to avoid unrealistic horizontal variations in forcing and simulated fields. 
Depending on temperature and the co-availability of photosynthetically active radiation (PAR) and nutrients, the model simulates primary production. Annual net carbon production per unit area is shown in Fig. 3d and simulated surface chl $a$ is compared to satellite observations in Figs. S4 and S5. The model broadly reproduces the temporal and spatial variability in primary production and chl $a$ observed across the shelf, although considerable improvements can be achieved through tuning of key model parameters (work in progress).

Surface production rates (Fig. 3d) and chl $a$ concentrations (Fig. S4) are especially high in shallow coastal water that remains well-mixed for most/all of the year, where nutrients are consequently continuously re-supplied from the seabed, and PAR levels are sufficient at all depths to maintain photosynthesis. We have limited confidence in the simulated primary production and chl $a$ close to the coasts, for two specific reasons. We do not account for the strong influence near many coasts of freshwater (runoff), which has an important stratifying influence on the water column. We also neglect the higher turbidity caused by non-algal particles that can reduce PAR below a level necessary to sustain photosynthesis, e.g. where sediment loads are relatively high in shallow regions of vigorous mixing, such as the southern North Sea. Recognizing this model limitation, we choose not to plot model output in water shallower than $30 \mathrm{~m}$ in Figs. 3 and S4.

Moving towards stratified regions, annual-mean carbon production rates generally decline, although remain above $55 \mathrm{~g} \mathrm{C} \mathrm{m}^{-2}$ year $^{-1}$ at most locations due to the combined result of the major spring and minor autumn blooms (see below). This decline is complemented by elevated productivity throughout summer at the thermocline, associated with the development and persistence of the SCM. Primary production rates during the spring bloom (not shown) reach $40 \mathrm{~g} \mathrm{C} \mathrm{m}^{-2} \mathrm{mon}^{-1}$ or $1333 \mathrm{mg} \mathrm{C} \mathrm{m}^{-2} \mathrm{~d}^{-1}$, in line with observed magnitudes of the order of $1000 \mathrm{mg} \mathrm{C} \mathrm{m}^{-3} \mathrm{~d}^{-1}$ (Rees et al., 1999). Summertime chl $a$ and primary production are low in the surface mixed layer, consistent with observed values of $<1 \mathrm{mg} \mathrm{chl} a \mathrm{~m}^{-3}$ and $5-30 \mathrm{mg} \mathrm{C} \mathrm{m}^{-3} \mathrm{~d}^{-1}$, respectively (Joint and Groom, 2000; Hickman et al., 2009). Simulated surface chl $a$ concentrations are broadly consistent with satellite observations, although values are typically double those observed (see Figs. S4 and S5). The model does not reproduce the enhanced primary production and chl $a$ observed in the surface at the Celtic Sea shelf break (e.g. compare Figs. S4 and S5, for April and May). This is likely because it does not include specific physical processes, such as the internal tide, that are important for vertical nutrient supply to the surface in these regions (Sharples et al., 2007).

Following the spring bloom, surface productivity and surface chl $a$ concentrations remain elevated (above background values) near three tidal mixing fronts in particular - the Ushant and western English Channel front, the Islay front, and the St George's Channel front - for June-September in the simulation (Fig. S4) and for May-July in the observa- tions (Fig. S5). Surface chl $a$ concentrations decline towards more stratified waters, coincident with deepening of the SCM away from fronts and associated zones of spring-neap frontal adjustment (Pingree et al., 1978; Weston et al., 2005; Hickman et al., 2012). At the Ushant front, predicted peak July primary production of $80-100 \mathrm{mg} \mathrm{C} \mathrm{m}^{-3} \mathrm{~d}^{-1}$ is considerably smaller than in situ measurements of $59-126 \mathrm{mg} \mathrm{C} \mathrm{m}^{-3} \mathrm{~h}^{-1}$ (implying daily production of around $1000 \mathrm{mg} \mathrm{m}^{-3} \mathrm{~d}^{-1}$ ), for surface waters at a frontal station in late July (Holligan et al., 1984). However, the model estimates are intermediate between corresponding surface observations for mixed and stratified waters (reported in Holligan et al., 1984), emphasising the very localized character of frontal productivity, which is not easily captured with our relatively coarse model resolution (here around $12 \mathrm{~km}$ ) and in the absence of horizontal processes that may lead to convergence of material at the front.

In the southern Irish Sea and south of the Islay front, simulated surface chl $a$ concentrations are notably very low, at around $0.1 \mathrm{mg} \mathrm{chl} a \mathrm{~m}^{-3}$ (see Fig. S4). These low values are found in regions where the tidal current amplitude is especially strong (see Fig. S1) in water that is sufficiently deep $(\sim 100 \mathrm{~m}$, see Fig. 1a) for PAR to fall below a threshold value within the well-mixed water column (Fig. 3b). So in spite of very high nutrient levels throughout the year (not shown), light is a severe limitation on photosynthesis and hence productivity. This aspect of the simulation is inconsistent with surface chl $a$ concentrations of around $1 \mathrm{mg} \mathrm{chl} a \mathrm{~m}^{-3}$ observed in this region (Fig. S5; Pemberton et al., 2004; Moore et al., 2006). A likely explanation is that the model does not resolve photo-acclimation, the known ability of phytoplankton to acclimate to ambient light conditions (e.g. Geider et al., 1997), and so does not resolve the photo-physiological differences between stratified and mixed water columns (Moore et al., 2006). DIN concentrations in the northwest European shelf region during winter and in the bottom mixed layer during summer (not shown) are $5-6 \mathrm{mmol} \mathrm{m}^{-3}$, consistent with observed values around 6-9 $\mathrm{mmol} \mathrm{m}^{-3}$ (Joint et al., 2001; Hickman et al., 2012).

To illustrate typical vertical structure across a mid-summer tidal mixing front, Fig. 4 shows observations and corresponding simulations for day 215 (3 August) of 2003, along a section through the Celtic Sea front (Fig. 4a), located at around $52^{\circ} \mathrm{N}$. The temperature distribution (Fig. $4 \mathrm{~b}, \mathrm{c}$ ) illustrates stratified water south of $52^{\circ} \mathrm{N}$, with mixed water to the north. DIN concentrations are high in mixed water and in the lower layer of the stratified water, and depleted in the surface layer of the stratified water (Fig. 4d, e). Chl $a$ concentrations reach a surface maximum at the front, with elevated values extending southwards in the model - the SCM supported by a weak diffusive DIN flux across the thermocline (Fig. 4f, g).

Comparing the simulation with the observations, the mixed water is about $1{ }^{\circ} \mathrm{C}$ cooler than observed, and DIN and chl $a$ concentrations are about $50 \%$ higher at most depths. Regarding structural discrepancy between observed chl $a$ 

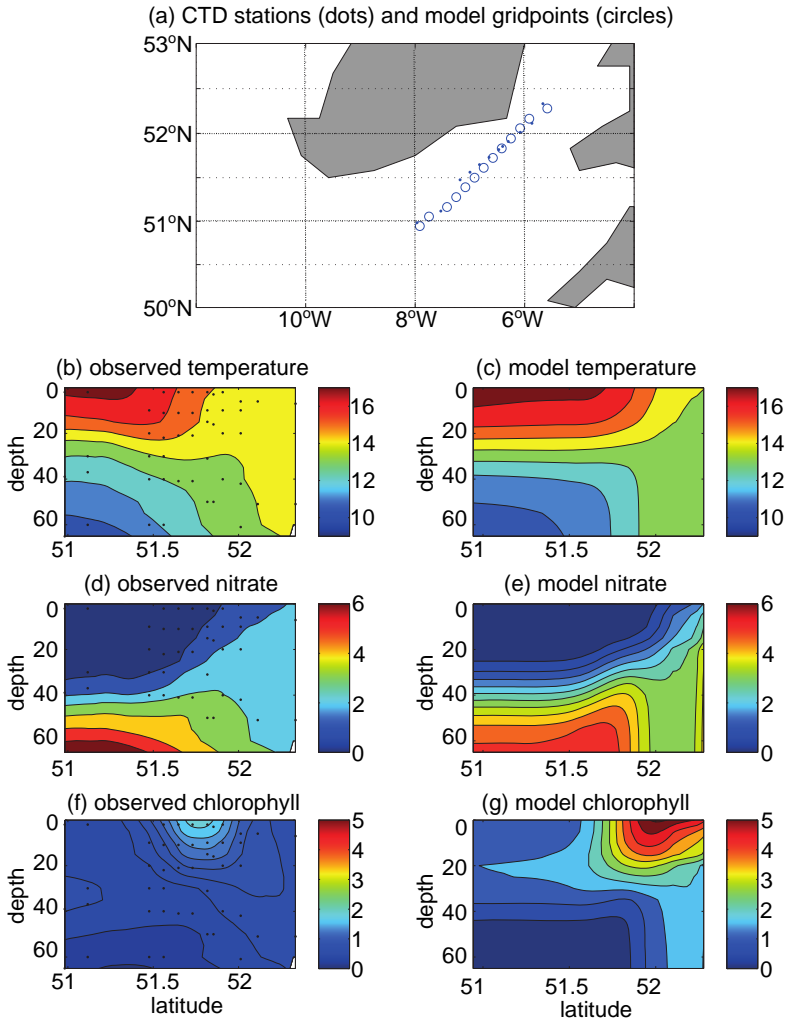

Figure 4. Sections through the Celtic Sea front around day 215 of 2003: (a) locations of CTD stations (dots) and model grid points (circles); (b, c) observed and modelled temperature $\left({ }^{\circ} \mathrm{C}\right)$; (d, e) observed and modelled dissolved inorganic nitrate (units mmol m${ }^{-3}$ ); (f, $\mathbf{g}$ ) observed and modelled chl $a$ concentration (units $\mathrm{mgchl} a \mathrm{~m}^{-3}$ ). The locations of observations in profile are indicated by dots in (b), (d) and (f).

concentrations in Fig. $4 \mathrm{f}$ and modelled chl $a$ concentrations in Fig. 4g, the northward-shifted surface maximum in the model is coincident with a more northward location of the tidal mixing front, which could be attributed to inadequacies in meteorological and/or tidal forcing. The higher surface maximum of $\operatorname{chl} a$ in the model may be in part due to neglected horizontal processes, such as along-front transports by a baroclinic jet supported by strong horizontal temperature gradients, and cross-frontal mixing processes associated with jet instability. Higher chl $a$ concentrations in the model may alternatively be attributed to the relatively simple description of phytoplankton physiology, grazing and mobility (no sinking, as default).

\subsection{Western English Channel}

For 1 May to 7 October of 2013, selected daily model fields are saved and animated (see Supplement Part B, "Example Animation", and accompanying commentary text). A wide range of phenomena are evident in the animation, including the earliest establishment of stratification during May,
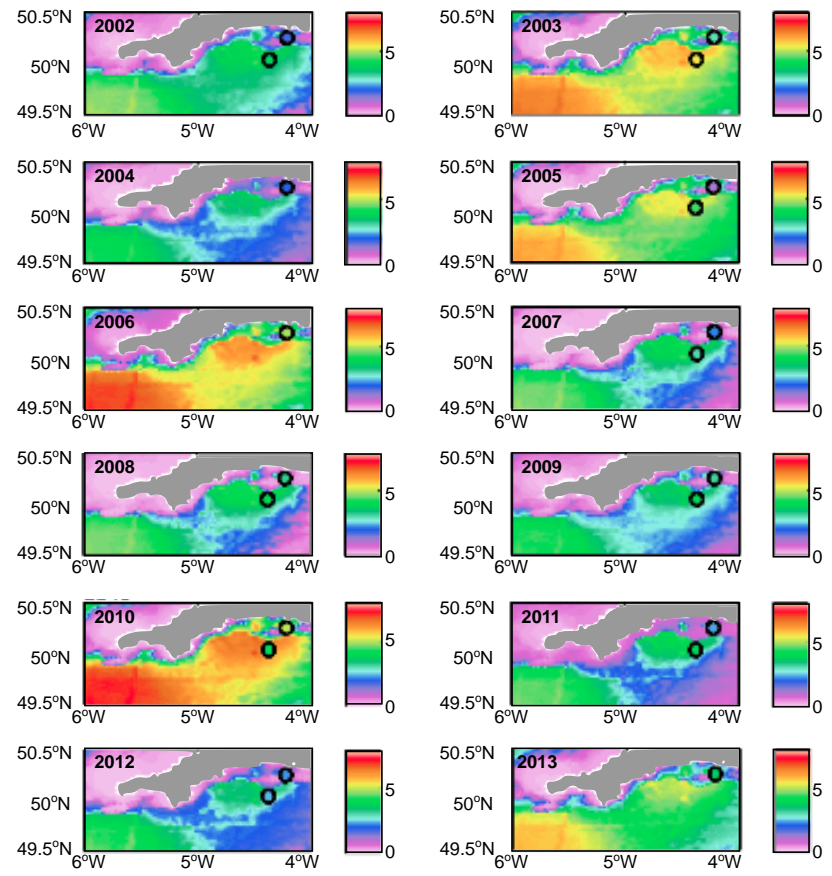

Figure 5. Surface-bottom temperature differences $\left({ }^{\circ} \mathrm{C}\right)$ in the western English Channel, on day 190 of 2002-2013. Coloured circles indicate the coincident temperature differences at L4 and E1, subject to data availability (E1 data are unavailable in 2004, 2006 and 2013).

expressed as a surface-bottom temperature difference, and the rapid uptake of surface DIN, which declines to near-zero concentrations with the development of a spring bloom (high surface chl $a$ levels) that peaks in early-mid June. We note that the exceptionally cold spring of 2013 substantially delayed the onset of stratification and the spring bloom (also suggested by satellite data - not shown). The spring-neap cycle of stronger mixing (on spring tides) and strengthened stratification (on neap tides) causes $\sim 14$-day "beating" of chl $a$ concentration, between low values on spring tides and high values on neap tides, most notably at the front between inshore mixed and offshore stratified waters off southwest Cornwall throughout June and July.

To illustrate the inter-annual variability of summer stratification, Fig. 5 shows surface-bottom temperature differences on day 190 (8 or 9 July) of 2002-2013. The region is characterized by mixed water to the northwest associated with locally strong tidal current amplitudes (see Fig. S1), and stratified water to the southwest (where tides are weaker), with a secondary area of stratification centred around $4.5^{\circ} \mathrm{W} 50.1^{\circ} \mathrm{N}$ (coincident with a local minimum in tidal current amplitude). The water column remains mixed all year round in shallow water close to the coast, at most locations and in most years. A complex arrangement of mixed and stratified water is simulated in the northeast of the region, associated with highly variable bathymetry 

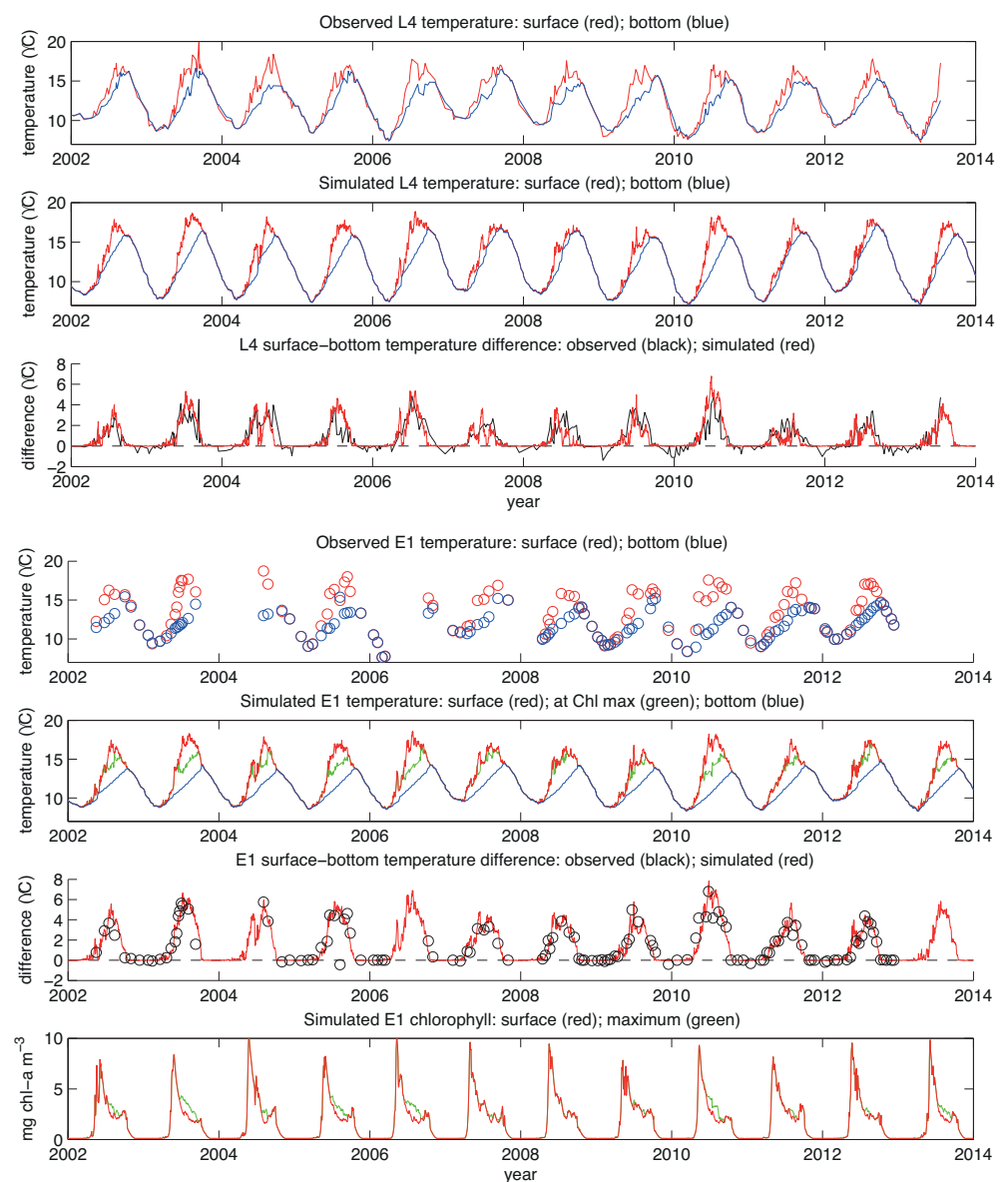

Figure 6. Time series of surface-bottom temperature differences observed and (daily) simulated at L4 and E1 (http://www. westernchannelobservatory.org.uk/data.php).

(see Fig. 1b). When a cold spring is followed by a warm summer (e.g. 2006, 2010, 2013), stratification is particularly strong, with surface-bottom temperature differences reaching almost $7{ }^{\circ} \mathrm{C}$ in the southwest of the region.

To locally validate the simulation, we use observations at L4 $\left(50^{\circ} 15.00^{\prime} \mathrm{N}, 4^{\circ} 13.02^{\prime} \mathrm{W}\right)$ and $\mathrm{E} 1$ $\left(50^{\circ} 02.00^{\prime} \mathrm{N}, 4^{\circ} 22.00^{\prime} \mathrm{W}\right)$, hydrographic stations that have been occupied weekly and monthly, respectively, as part of the Western Channel Observatory (http://www.westernchannelobservatory.org.uk/data.php).

Here, seasonal cycles of stratification and phytoplankton dynamics have been extensively studied (Smyth et al., 2010). In Fig. 5, we overplot observed temperature differences for station occupations within a few days (L4) or 1-2 weeks (E1) of day 190. Observed differences are generally indistinguishable from the simulated differences.

For a more comprehensive validation, Fig. 6 shows time series of surface-bottom temperature differences observed and (daily) simulated at L4 and E1. The temperature at the depth of the maximum chl $a$ concentration is also plotted at E1, confirming the existence of an SCM within the sea- sonal thermocline. Starting on 1 January 2002, we simulate 1 year at a time, specifying a mixed water column temperature on, e.g. 1 January 2003 with the corresponding temperature on 31 December 2002. This ensures continuity in temperatures between years, respecting a small degree of inter-annual variability in wintertime temperature at L4 and E1. Weak stratification (maximum $\sim 4^{\circ} \mathrm{C}$ ) typically is established over $\sim 5$ months of each summer at L4, while stronger stratification (up to $\sim 7^{\circ} \mathrm{C}$ ) develops for longer (by 1-2 months) at E1. Model-observation agreement is remarkably good, with close correspondence between not just surface temperatures, but also bottom temperatures. The seasonally varying stratification at both stations is generally reproduced to within $1{ }^{\circ} \mathrm{C}$, although high-frequency extremes are undersampled by weekly (monthly) occupations of L4 (E1), and there is more disagreement at L4. This is most likely because the water column at L4 is strongly influenced by freshwater, with low surface salinity having a substantial effect on stratification. The vertical salinity distribution also explains the apparent temperature instability (negative surfacebottom temperature differences) observed at L4 in winter - 

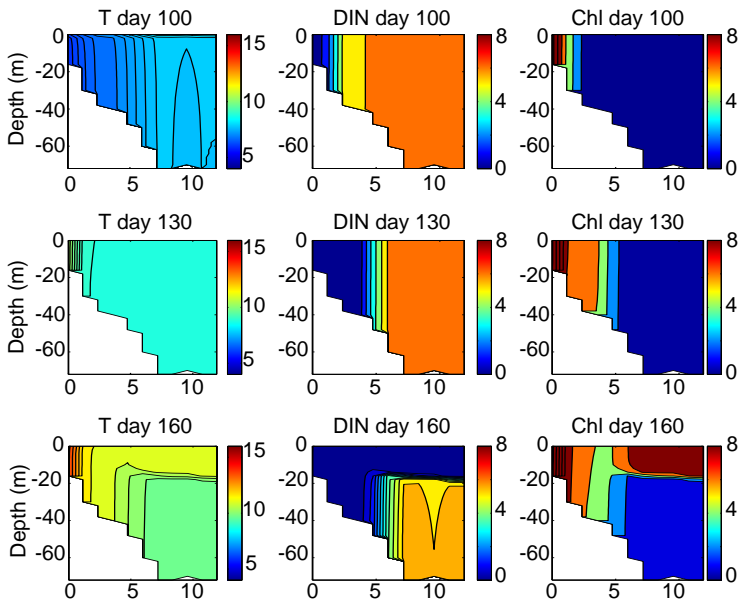

Chl day 160
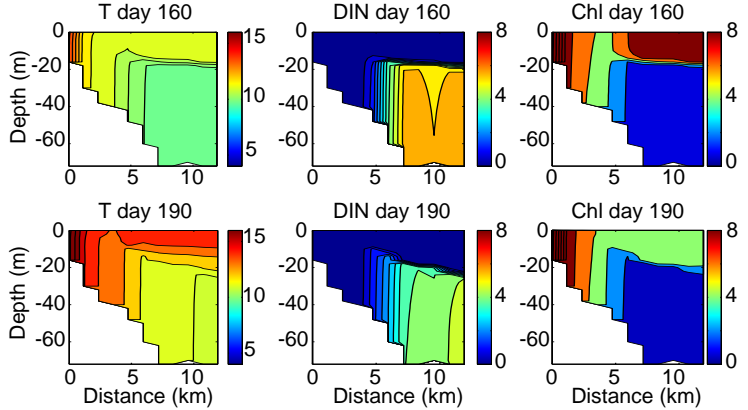

Figure 7. Sections through the developing tidal mixing front east of Lizard peninsula, along $50.017^{\circ} \mathrm{N}$, on days 100, 130, 160 and 190 of 2013: temperature (left column); dissolved inorganic nitrate ( $\mathrm{mmol} \mathrm{m}{ }^{-3}$, middle column); chl $a$ ( $\mathrm{mg} \mathrm{chl} a \mathrm{~m}^{-3}$, right column).

the water column is in fact statically stable throughout the time series.

With some confidence in model performance, in Fig. 7 we show temperature, DIN and chl $a$ in sections through the developing tidal mixing front east of Lizard peninsula, along $50.017^{\circ} \mathrm{N}$, on days $100,130,160$ and 190 of 2013 . We select this section as representative of CTD transects undertaken annually in late June/early July by University of Southampton fieldwork students. On day 100 (early April), the water column is well-mixed almost everywhere, with very weak stratification in temperature evident at $10 \mathrm{~km}$ along the section. DIN concentrations are high $\left(\sim 6 \mathrm{mmol} \mathrm{m}^{-3}\right)$ throughout the water column for bottom depths exceeding a threshold value $(\sim 40 \mathrm{~m})$, below which PAR falls below a critical value within the water column. As bottom depths become shallower (progressing inshore), DIN concentrations rapidly fall to near zero, where PAR is sufficient at all depths to sustain plankton growth and associated DIN uptake in the model. Inshore chl $a$ concentrations are accordingly high (12-13 $\left.\mathrm{mg} \mathrm{chl} a \mathrm{~m}^{-3}\right)$, falling rapidly with distance to background values $\left(\sim 0.1 \mathrm{mg} \mathrm{chl} a \mathrm{~m}^{-3}\right)$ offshore.

By day 130 (early May), the water remains well-mixed, although warmer by $1-2{ }^{\circ} \mathrm{C}$, and high productivity has spread offshore, presumably due to intermittent weak stratification during preceding days. By day 160, stratification is clearly established beyond $4 \mathrm{~km}$ offshore. DIN concentrations are now reduced to near-zero in the upper $20 \mathrm{~m}$ of the stratified water, and high chl $a$ concentrations are evidence of the spring bloom. By day 190, stratification has strengthened and DIN concentrations in the deep layer of stratified water columns are further depleted through vertical mixing with the upper photic zone, although surface chl $a$ concentrations have by this time substantially declined in the upper layer. The boundary between mixed and stratified waters on days 160 and 190 marks the position of the tidal mixing front. The model has been further used to evaluate the extent of inter-annual variability around the time of annual fieldwork, in the third week of June. Temperature sections on day 169 of 2002-2013 (see Fig. S6) reveal a wide range of offshore stratification and frontal structure in recent years, with the strongest stratification in 2010, the weakest stratification in 2011, and a most clearly defined front in 2009.

As an example of the seasonal cycles in temperature, surface DIN and surface chl $a$ at four locations across the front (spanning the distance range 3-7 $\mathrm{m}$ in Fig. S6), Fig. 8 shows evolution of these variables through 2013. Stratification is very marginal and intermittent at $5.033^{\circ} \mathrm{W}$, with surfacebottom temperature differences occasionally reaching $2{ }^{\circ} \mathrm{C}$. DIN concentrations fall close to zero over days $130-300$ and chl $a$ concentrations are high (in the range 6-8 $\mathrm{mg}$ chl $a \mathrm{~m}^{-3}$ ) throughout this period. Related to the intermittent stratification are similar fluctuations in $\operatorname{chl} a$. This variability is in part attributed to the near-fortnightly spring-neap tidal cycle, which leads to periodic replenishment of nutrients, out of phase with more favourable PAR regimes. Progressing offshore into deeper water, the seasonal cycle transforms towards stronger stratification, a shorter period of surface DIN reduction, and a stronger peak in surface chl $a$ around day 150 that corresponds to the spring bloom, followed by substantially lower concentrations during the rest of summer.

\subsection{East China and Yellow seas}

Figure 9 shows example fields for a simulation using the East China Sea and Yellow Sea domain with 2013 forcing. Figure 9a shows the annual-mean Hunter-Simpson parameter, $\log _{10}\left(h / u^{3}\right)$, which falls below 2.7 in particularly shallow regions (see Fig. 1c) that are also characterized by high amplitude tidal currents (see Fig. S2); $\log _{10}\left(h / u^{3}\right)$ conversely exceeds 5.0 in the isolated Bohai Sea, lying to the northwest of the Yellow Sea. As for the northwest European shelf, regions with $\log _{10}\left(h / u^{3}\right)<2.7$ remain well-mixed throughout summer (Fig. 9b). Elsewhere, stratification is stronger than for the northwest European shelf, with surface-bottom temperature differences on day 190 of $\sim 10^{\circ} \mathrm{C}$ across much of the stratified shelf. A major feature of Fig. $9 b$ is the front between mixed and stratified water in the East China Sea that is clearly observed in satellite SST data (Hickox et al., 2000). The simulations also capture the complex system of fronts observed in the Taiwan Strait (Zhu et al., 2013).

The specification of common meteorological variables across $\sim 20^{\circ}$ of latitude and $\sim 15^{\circ}$ of longitude is a considerable approximation, and the annual-mean net surface 

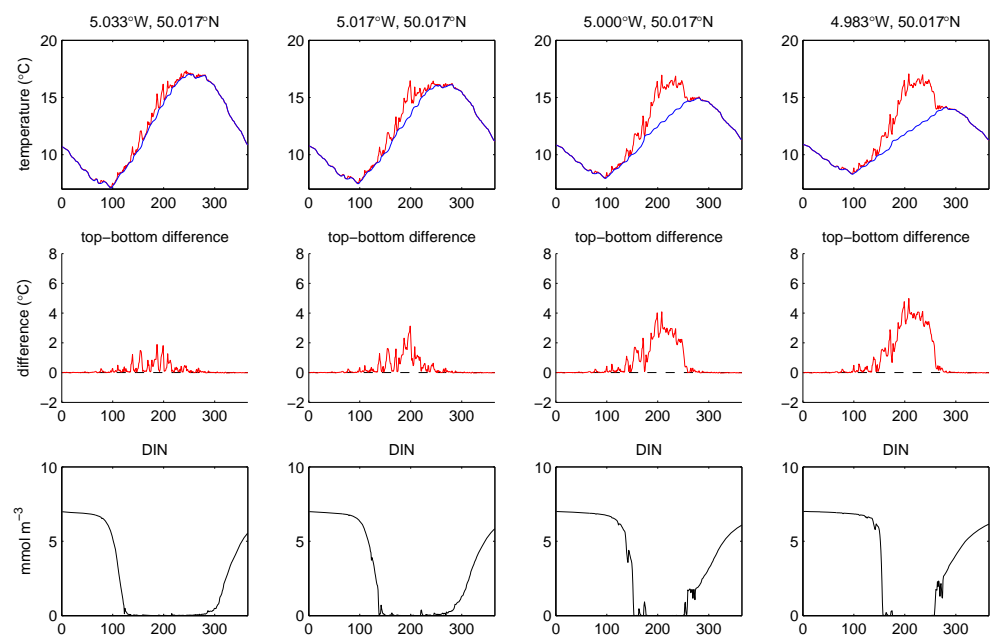

DIN
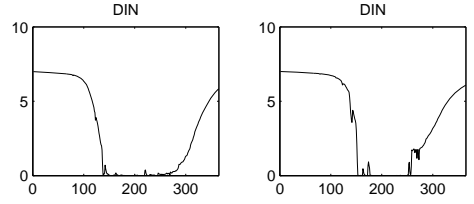

DIN
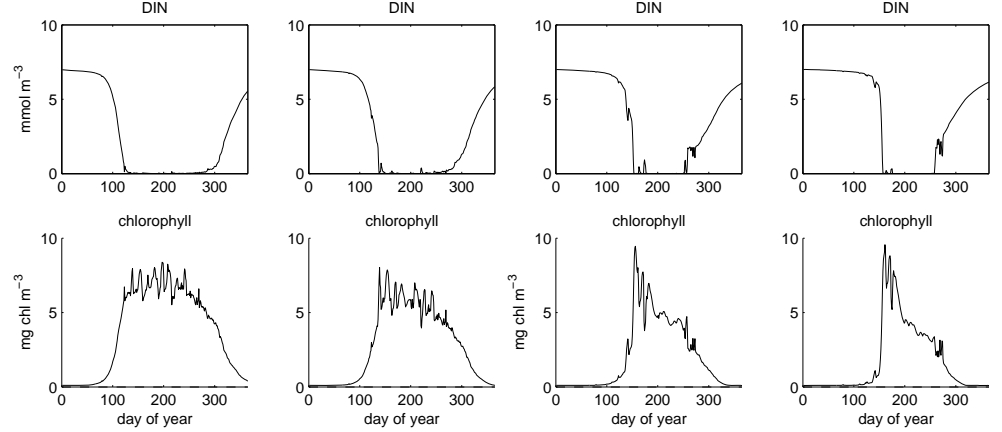

Figure 8. Time series of surface and bottom temperature (red and blue curves), surface-bottom temperature difference, surface DIN and surface chl $a$ concentrations, across the tidal mixing front east of the Lizard peninsula in 2013.

heat flux field is an important measure of resulting heat imbalances (Fig. 9c). We regard these values as not too excessive, ranging from around $5 \mathrm{~W} \mathrm{~m}^{-2}$ (heat gain) in the far south to around $-10 \mathrm{~W} \mathrm{~m}^{-2}$ (excess heat loss) in the far north (Bohai Sea). Annual-mean carbon production rates in the well-mixed shallow regions of the East China Sea range from 300 to $450 \mathrm{~g} \mathrm{C} \mathrm{m}^{-2}$ year $^{-1}$, falling to $\sim 100 \mathrm{~g} \mathrm{C} \mathrm{m}^{-2}$ year $^{-1}$ in the more extensive stratified region (Fig. 9d). These predictions are similar in magnitude to estimates of primary production based on in situ observations (e.g. $145 \mathrm{~g} \mathrm{C} \mathrm{m}^{-2}$ year $^{-1}$ for "the entire shelf of the East China Sea", Gong et al., 2003). Monthly mean surface chl $a$ distributions are broadly comparable to satellite observations, although maximum model chl $a$ concentrations are generally double those observed, and the spring bloom is $\sim 1$ month late, in May rather than April (e.g. for 2013, Figs. S7 and S8). Discrepancies between the model and observations in this region may be improved by accounting for higher turbidity in relatively shallow water and model refinements related to photo-physiology.

To complete the 3-D picture, Fig. 10 shows show temperature, DIN and chl $a$ concentration in sections through the developing front of the central East China Sea, along $32^{\circ} \mathrm{N}$, on days $100,130,160$ and 190 of 2013. Bottom depth increases considerably with distance offshore. In water of depth $<40 \mathrm{~m}$, the water column remains well-mixed throughout the year, while in deeper water, stratification becomes established between days 100 and 130. In stratified water, DIN is already depleted in the surface layer over days $100-130$, and is gradually further depleted in the lower layer over days 130-190 through progressive mixing into the photic zone. A local surface maximum in chl $a$ concentration is evident at the frontal boundary $(\sim 250 \mathrm{~km})$ on day 130 , while a SCM is evident in stratified water on days 160 and 190. The SCM is most clearly defined at $\sim 25 \mathrm{~m}$ on day 190 .

\section{Summary and discussion}

We have developed S2P3-R, a versatile framework for efficient modelling of physical and biological phenomena and processes in shelf seas, adopting an existing 1-D model, S2P3. Here, we complement ongoing development and use of the 1-D model for specific research hypotheses (e.g. Bauer and Waniek, 2013) and in educational settings, where idealized simulations (e.g. Sharples, 2008) are linked to realistic situations such as fieldwork contexts - e.g. off Cornwall, away from the lateral influences of runoff.

The realism of S2P3-R depends on the extent to which vertical processes dominate horizontal processes. This is evident across some shelf sea regions, where we have the high-quality observations necessary for a co-evaluation of these processes. One way to formally quantify the dominance of surface net heat fluxes and tidal plus wind mixing (the 1-D processes) is by calculating tendencies of the potential energy anomaly (PEA; see Chapter 6 in Simpson and Sharples, 2012). PEA tendencies calculated directly from observed changes of stratification at selected locations (e.g. weekly/monthly at Western Channel Observatory stations 

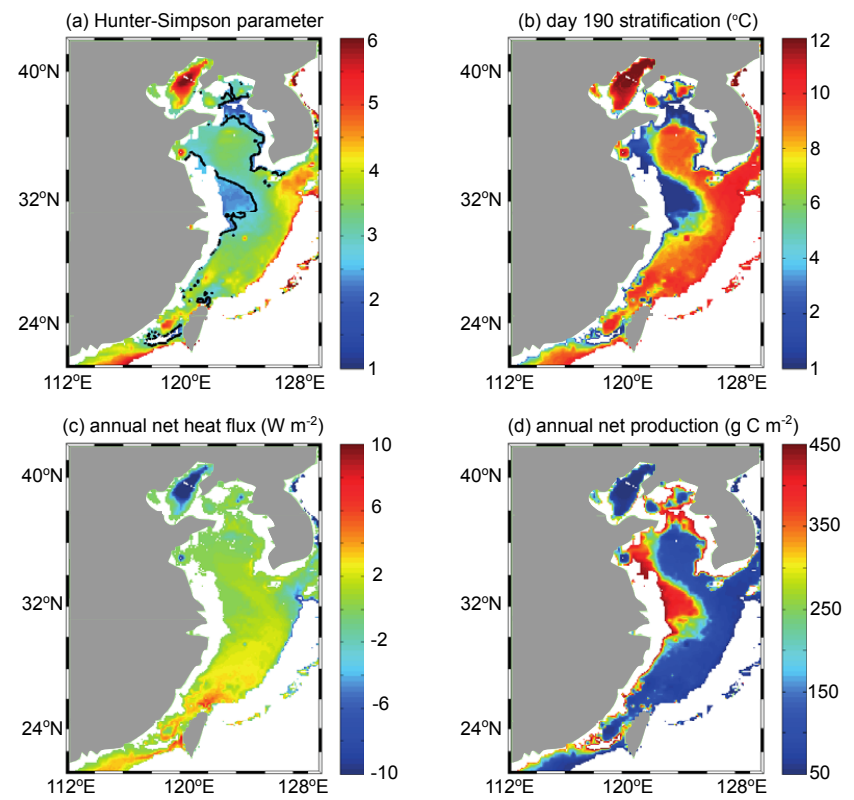

Figure 9. For the East China and Yellow seas domain in 2013: (a) Hunter-Simpson parameter, highlighting the contour delineating $\log _{10}\left(h / u^{3}\right)=2.7$; (b) day 190 surface-bottom temperature difference; (c) net surface heat flux; (d) annual net production.

L4/E1) can be compared with indirect estimates computed from time-integrated heat fluxes, winds and tidal currents at the same locations. If local heat fluxes and tidal/wind mixing dominate the annual cycle of stratification, directly calculated and indirectly estimated time series of PEA tendency should be similar.

Where appropriate, the framework facilitates experiments to investigate the sensitivity of measurable quantities (e.g. chl $a$ concentration) to a wide range of physical and biological processes that can be adjusted with corresponding model parameters. Where high-quality observations are available (e.g. at E1 in the western English Channel), S2P3-R thus provides a means for improving our fundamental understanding of the system. With tuned parameters, S2P3-R furthermore provides the means to carry out credible multi-year simulations of physical and biological processes and property distributions at appropriately high temporal, vertical and horizontal resolution.

At the seasonal timescale, the most striking surface features are TMFs. Realistic representation of TMFs, demanding high horizontal resolution, amounts to first-order evaluation of any simulation, e.g. the UK Met Office forecast system (O'Dea et al., 2012), which has the same relatively coarse $(12 \mathrm{~km})$ resolution as our northwest European shelf domain. The summer surface-bottom temperature differences across the northwest European shelf and the associated TMFs in S2P3-R (Fig. 3a) compare well with the 3-D model results (O'Dea et al., 2012, their Fig. 10). Our simpler approach thus indicates the importance of 1-D processes in forming these features, the locations of which are consistent with these more complex models.

It is natural to deploy $\mathrm{S} 2 \mathrm{P} 3$ across multiple processors, with sub-domains computed independently in parallel. This has been trialled for twelve $1^{\circ} \times 1^{\circ}$ sub-domains across the southern Celtic Sea and western English Channel at a resolution of $1 \mathrm{~km}$, substantially expanding our western English Channel domain with essentially no extra computational expense. Figure 11 shows the July surface-bed temperature difference across this region, illustrating how we are able to efficiently simulate regional stratification at very high horizontal resolution.

We have evaluated the model in various ways with available observations, specifically addressing spatial patterns, vertical structures, and seasonal-interannual variability. Temperature distributions are reproduced with considerable success, as are key aspects of the spatial and temporal variability in nutrient and chl $a$ concentrations. In particular, we are able to accurately reproduce monthly observations of thermal structure at station E1 in the western English Channel over 2002-2013 (Fig. 6), providing confidence in the use of S2P3-R in this region. We therefore consider there is much potential for S2P3-R to investigate physical and physiological controls on primary productivity at regional scales.

Elsewhere, differences between the model and observations are informative because, for example, they identify regions in which processes other than those represented in the model are important. In particular, we note several processes specific to coasts and shelf breaks, of relevance to several physical aspects of the domains considered here: 

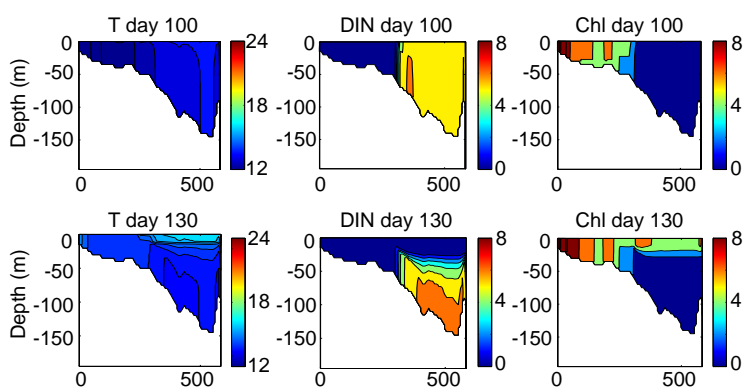

DIN day 130
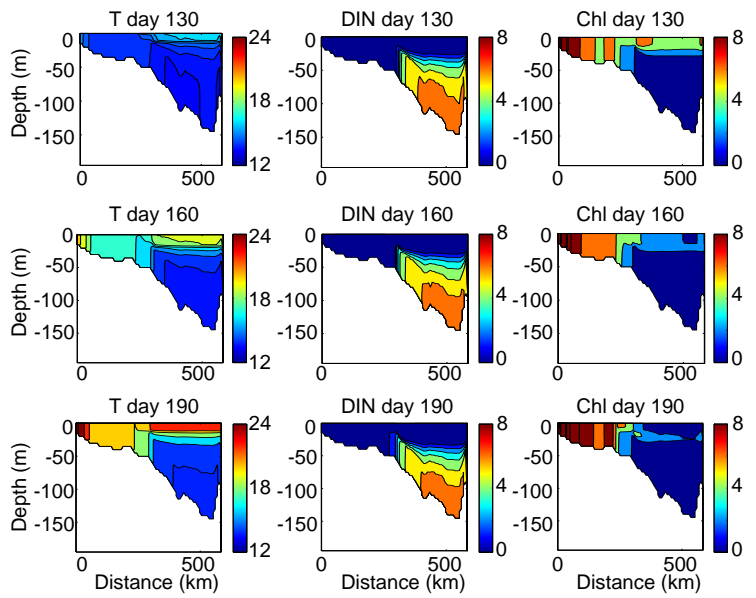

Figure 10. Sections through the developing tidal mixing front of the East China Sea, along $32^{\circ} \mathrm{N}$, on days 100, 130, 160 and 190 of 2013: temperature (left column); DIN ( $\mathrm{mmol} \mathrm{m}^{-3}$, middle column); chl $a$ (mg chl $a \mathrm{~m}^{-3}$, right column).

- The coastal zone around Cornwall, typified by station L4, is strongly influenced by riverine inputs that promote surface freshening and stratification and alter light attenuation by non-algal particles and dissolved organic matter (Groom et al., 2009; Smyth et al., 2010).

- The northern North Sea is strongly influenced by shelf edge exchange that leads to the inflow of relatively warm and salty Atlantic Water (Huthnance et al., 2009).

- The Yangtze River and two branches of the Kuro Shio - the Taiwan current and the Tsushima warm current exert strong influences on stratification and productivity in the East China Sea (e.g. Son et al., 2006).

Further development of S2P3-R will formally establish the (presently prototype) option to prescribe spatially variable initial temperatures and meteorological variables, interpolated appropriately to each model mesh. As an additional diagnostic, the thermal wind balance may be used with the simulated density field to infer the residual flows that are associated with TMFs (e.g. Hill et al., 2008), indicating the potential importance of net advection along the fronts.

In summary, the S2P3-R framework (v1.0) provides the flexibility to undertake research experiments in finely resolved realistic domains where 1-D processes dominate, to test hypotheses regarding the sensitivity of 1-D biogeochemical processes to key model parameters, and/or to test the responses to variations of physical forcing on timescales ranging from diurnal to inter-annual. Combining flexibility with

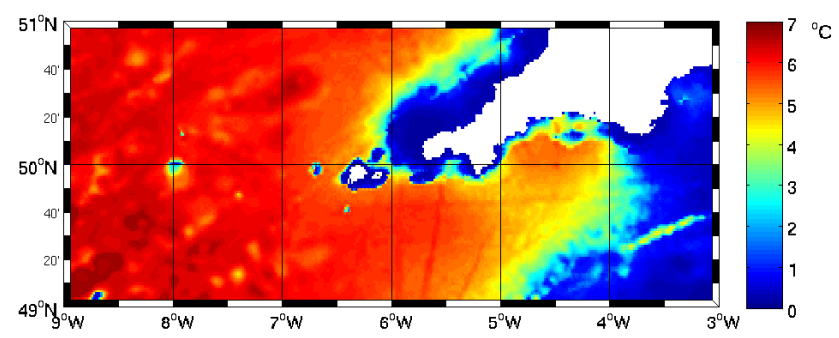

Figure 11. Surface-bottom temperature differences $\left({ }^{\circ} \mathrm{C}\right)$ across the southern Celtic Sea and western English Channel, in mid-July of 2014 , simulated with S2P3-R configured in twelve $1^{\circ} \times 1^{\circ}$ subdomains, as indicated.

computational efficiency, the S2P3-R framework may further contribute to capacity building in marine monitoring and management for individuals/organisations without the resources to run or analyse complex models of their territorial waters or exclusive economic zones.

\section{Code availability}

The S2P3-R (v1.0) framework, comprising source code along with example scripts and output, is available online from ftp://ftp.noc.soton.ac.uk/pub/rma/s2p3-reg.tar.gz.

Unzipped and uncompressed, the directory/s2p3_reg_v1 contains several sub-directories:

- /main contains the source code, s2p3v7_reg_v1.f90, which is compiled "stand alone", and executed using accompanying scripts, with examples of "map" (the northwest European Shelf simulation, as Fig. 3), "section" (Celtic Sea) and "time series" (E1) simulations (run_map, run_section and run_timeseries, respectively).

- /domain contains bathymetry and tide data for the northwest European Shelf region (s12_m2_s2_n2_h_map.asc), for a selected north-south section in the Celtic Sea (s12_m2_s2_n2_h_sec.asc) and for a selected point, E1 in the western English Channel (s12_m2_s2_n2_h_tim.asc).

- /met contains climatological meteorological forcing (Celtic_met.dat).

- /output contains example output data from the three runs (map, section, time series).

- /plotting contains MATLAB scripts for plotting maps, sections and time series (plot_map, plot_section and plot_timeseries, respectively).

The ancillary files needed for simulations in the domains "western English Channel" and "East China and Yellow seas", and for a selection of years, are available on request from the author (e-mail rm12@ soton.ac.uk). 


\section{The Supplement related to this article is available online at doi:10.5194/gmd-8-3163-2015-supplement.}

Acknowledgements. Jeff Blundell assisted with initial editing of the S2P3 source code. Ivan Haigh ran the OSU Tidal Prediction Software to predict tidal current amplitudes in the East China and Yellow seas. Data at L4 and E1 were downloaded from http://www.westernchannelobservatory.org.uk/data with thanks to the Western Channel Observatory community. R. Marsh acknowledges the support of a 2013 Research Bursary awarded by the Scottish Association for Marine Science. A. E. Hickman was partly funded by a Natural Environment Research Council fellowship (NE/H015930/2). We thank three anonymous reviewers for a series of insightful comments that helped us to focus the paper.

Edited by: A. Yool

\section{References}

Amante, C. and Eakins, B. W.: ETOPO1 1 Arc-Minute Global Relief Model: Procedures, Data Sources and Analysis. NOAA Technical Memorandum NESDIS NGDC-24, 19 pp., 2009.

Bauer, A. and Waniek, J. J.: Factors affecting the chlorophyll a concentration in the central Beibu Gulf, South China Sea, Mar. Ecol. Prog. Ser., 474, 67-88, doi:10.3354/meps10075, 2013.

Edwards, K. P., Barciela, R., and Butenschön, M.: Validation of the NEMO-ERSEM operational ecosystem model for the North West European Continental Shelf, Ocean Sci., 8, 983-1000, doi:10.5194/os-8-983-2012, 2012.

Egbert, G. D. and Erofeeva, S. Y.: Efficient Inverse Modeling of Barotropic Ocean Tides, J. Atmos. Ocean. Tech., 19, 183-204, doi:10.1175/1520-0426(2002)019<0183:EIMOBO>2.0.CO;2, 2002.

Egbert, G. D., Bennett, A. F., and Foreman, M. G. G.: TOPEX/POSEIDON tides estimated using a global inverse model, J. Geophys. Res., 99, 24821-24852, doi:10.1029/94JC01894, 1994.

Geider, R. J., MacIntyre, H. L., and Kana, T. M.: A dynamic model of phytoplankton growth and acclimation: responses of the balanced growth rate and chlorophyll $a$ : carbon ratio to light, nutrient-limitation and temperature, Mar. Ecol. Prog. Ser., 148, 187-200, 1997.

Gong, G.-C., Wen, Y.-H., Wang, B.-W., and Liu, G.-J.: Seasonal variation of chlorophyll a concentration, primary production and environmental conditions in the subtropical East China Sea, Deep-Sea Res. Pt. II, 50, 1219-1236, 2003.

Groom, S., Martinez-Vicente, V., Fishwick, J., Tilstone, G., Moore, G., Smyth, T., and Harbour, D.: The Western English Channel Observatory: optical characteristics of station L4, J. Marine Syst., 77, 278-295, 2009.

Hickman, A. E., Holligan, P. M., Moore, C. M., Sharples, J., Krivtsov, V., and Palmer, M. R.: Distribution and chromatic adaptation of phytoplankton within a shelf sea thermocline, Limnol. Oceanogr., 54, 525-536, 2009.
Hickman, A. E., Moore, C. M., Sharples, J., Lucas, M. I., Tilstone, G. H., Krivtsov, V., and Holligan, P. M.: Primary production and nitrate uptake within the seasonal thermocline of a stratified shelf sea, Mar. Ecol. Prog. Ser., 463, 39-57, doi:10.3354/meps09836, 2012.

Hickox, R., Belkin, I., Cornillon, P., and Shan, Z.: Climatology and Seasonal Variability of Ocean Fronts in the East China, Yellow and Bohai Seas from Satellite SST Data, Geophy. Res. Lett., 27, 2945-2948, 2000.

Hill, A. E., James, I. D., Linden, P. F., Matthews, J. P., Prandle, D., Simpson, J. H., Gmitrowicz, E. M., Smeed, D. A., Lwiza, K. M. M., Durazo, R., Fox, A. D., and Bowers, D. G.: Dynamics of tidal mixing fronts in the North Sea [and discussion], Philos. T. R. Soc. Lond., 343, 431-446, 1993.

Hill, A. E., Brown, J., Fernand, L., Holt, J., Horsburgh, K. J., Proctor, R., Raine, R., and Turrell, W. R.: Thermohaline circulation of shallow tidal seas, Geophys. Res. Lett., 35, L11605, doi:10.1029/2008GL033459, 2008.

Holligan, P. M., Williams, P. J. L., Purdie, D., and Harris, R. P.: Photosynthesis, respiration and nitrogen supply of plankton populations in stratified, frontal and tidally mixed shelf waters, Mar. Ecol. Prog. Ser., 17, 201-213, 1984.

Holt, J., Harle, J., Proctor, R., Michel, S., Ashworth, M., Batstone, C., Allen, I., Holmes, R., Smyth, T., Haines, K., Bretherton, D., and Smith, G.: Modelling the global coastal ocean, Philos. T. R. Soc. A, 367, 939-951, doi:10.1098/rsta.2008.0210, 2009a.

Holt, J., Wakelin, S., and Huthnance, J.: Down-welling circulation of the northwest European continental shelf: A driving mechanism for the continental shelf carbon pump, Geophys. Res. Lett., 36, L14602, doi:10.1029/2009GL038997, 2009b.

Huthnance, J. M., Holt, J. T., and Wakelin, S. L.: Deep ocean exchange with west-European shelf seas, Ocean Sci., 5, 621-634, doi:10.5194/os-5-621-2009, 2009.

Joint, I. and Groom, S. B.: Estimation of phytoplankton production from space: current status and future potential of satellite remote sensing, J. Exp. Mar. Biol. Ecol., 250, 233-255, 2000.

Joint, I., Wollast, R., Chou, L., Batten, S., Elskens, M., Edwards, E., Hirst, A., Burkill, P., Groom, S., Gibb, S., Miller, A., Hydes, D., Dehairs, F., Antia, A., Barlow, R., Rees, A., Pomroy, A., Brockmann, U., Cummings, D., Lampitt, R., Loijens, M., Mantoura, F., Miller, P., Raabe, T., Alvarez-Salgado, X., Stelfox, C., and Woolfenden, J.,: Pelagic production at the Celtic Sea shelf break, Deep-Sea Res., 48, 3049-3081, doi:10.1016/S09670645(01)00032-7, 2001.

Kalnay, E., Kanamitsu, M., and Kistler, R.: The NCEP/NCAR 40year reanalysis project, B. Am. Meteor. Soc., 77, 437-470, 1996.

Moore, C. M., Suggett, D., Holligan, P. M., Sharples, J., Abraham, E. R., Lucas, M. I., Rippeth, T. P., Fisher, N. R., Simpson, J. H., and Hydes, D. J.: Physical controls on phytoplankton physiology and production at a shelf sea front: a fast repetition-rate fluorometer based field study, Mar. Ecol. Prog. Ser., 259, 29-45, 2003.

Moore, C. M., Suggett, D. J., Hickman, A. E., Kim, Y. N., Tweddle, J. F., Sharples, J., Geider, R. J., and Holligan, P. M.: Phytoplankton photoacclimation and photoadaptation in response to environmental gradients in a shelf sea, Limnol. Oceanogr., 51, 936-949, 2006.

O’Dea, E. J., Arnold, A. K., Edwards, K. P., Furner, R., Hyder, P., Martin, M. J., Siddom, J. R., Storkey, D., While, J., Holt, J. T., and Liu, H.: An operational ocean forecast system incorporating 
NEMO and SST data assimilation for the tidally driven European North-West shelf, Journal of Operational Oceanography, 5, 3-17, 2012.

Pemberton, K., Rees, A. P., Miller, P. I., Raine, R., and Joint, I.: The influence of water body characteristics on phytoplankton diversity and production in the Celtic Sea, Cont. Shelf Res., 24, 2011-2028, 2004.

Pingree, R., Holligan, P., and Mardell, G. T.: The effects of vertical stability on phytoplankton distributions in the summer on the northwest European Shelf, Deep Sea Res., 25, 1011-1028, 1978.

Rees, A. P., Joint, I., and Donald, K. M.: Early spring bloom phytoplankton-nutrient dynamics at the Celtic Sea Shelf Edge, Deep-Sea Res. Pt. II, 46, 483-510, 1999.

Sharples, J.: Investigating the seasonal vertical structure of phytoplankton in shelf seas, Marine Models Online, 1, 3-38, 1999.

Sharples, J.: Potential impacts of the spring-neap tidal cycle on shelf sea primary production, J. Plankton Res., 30, 183-197, 2008.

Sharples, J., Ross, O. N., Scott, B. E., Greenstreet, S., and Fraser, H.: Inter-annual variability in the timing of stratification and the spring bloom in the North-western North Sea, Cont. Shelf Res., 26, 733-751, 2006.

Sharples, J., Tweddle, J. F., Green, J. A. M., Palmer, M. R., Kim, Y.-N., Hickman, A. E., Holligan, P. M., Moore, C. M., Rippeth, T. P., Simpson, J. H., and Krivtsov, V.: Spring-neap modulation of internal tide mixing and vertical nitrate fluxes at a shelf edge in summer, Limnol. Oceanogr., 52, 1735-1747, 2007.
Simpson, J. H. and Bowers, D. G.: Geographical variations in the seasonal heating cycle in northwest European shelf seas, Annales Geophysicae, 2, 411-416, 1984.

Simpson, J. H. and Hunter, J. R.: Fronts in the Irish Sea, Nature, 250, 404-406, 1974.

Simpson, J. H. and Sharples, J.: Introduction to the Physical and Biological Oceanography of Shelf Seas, Cambridge University Press, Cambridge, UK, 2012.

Smyth, T. J., Fishwick, J. R., Al-Moosawi, L., Cummings, D. G., Harris, C., Kitidis, V., Rees, A., Martinez-Vicente, V., and Woodward, E. M. S.: A broad spatio-temporal view of the Western English Channel observatory, J. Plankton Res., 32, 585-601, doi:10.1093/plankt/fbp128, 2010.

Son, S., Yoo, S., and Noh, J.-H.: Spring phytoplankton bloom in the fronts of the East China Sea, Ocean Sci. J., 41, 181-189. doi:10.1007/BF03022423, 2006.

Weston, K., Fernand, L., Mills, D., Delahunty, R., and Brown, J.: Primary production in the deep chlorophyll maximum of the central North Sea, J. Plankton Res., 27, 909-922, 2005.

Zhu, J., Hu, J., and Liu, Z.: On summer stratification and tidal mixing in the Taiwan Strait, Frontiers of Earth Science, 7, 141-150, doi:10.1007/s11707-013-0355-1, 2013. 